\title{
Detection of Vibrioes in the Aquatic Environment and the Sewage System by Culture Method in Selected Areas in Yemen
}

\author{
Mohammed F Al-Helali ${ }^{1}$, Nisreen Yahya Al-Kahtani ${ }^{1}$ and Hassan A Al-Shamahy ${ }^{2 *}$ \\ ${ }^{1}$ The Biology Department, Faculty of Sciences, Sana'a University, Yemen \\ ${ }^{2}$ Department of Medical Microbiology, Sana'a University, Yemen
}

*Corresponding author: Hassan A Al-Shamahy, Department of Medical Microbiology, Faculty of Medicine and Health Sciences, Sana'a University, P.O. Box 775 Sana'a -Yemen.

To Cite This Article: Hassan A Al-Shamahy. Detection of Vibrioes in the Aquatic Environment and the Sewage System by Culture Method in Selected Areas in Yemen. Am J Biomed Sci \& Res. 2019 - 3(6). AJBSR.MS.ID.000739. DOI: 10.34297/AJBSR.2019.03.000739

Received: December 12, 2018 | Published: July 11, 2019

\begin{abstract}
Water sources contamination is nearly always the result of human activities and drinking water source is especially vulnerable in areas where population density is high and human use of the land is extensive. When water sources become contaminated, it is difficult to purify. Liquid waste discharged on to the soil initiates solute and microbe movements are the main source that contaminates water sources. Thus far, there are no records of any studies in which Vibrioes contaminations have been studied in aquatic environment in Yemen, so in the present study, we tried to isolate vibrioes in Thiosulfate citrate bile salt media (TCBS) selective media from different sources of drinking water, in addition from swages system in Sana'a city.

A hundred and thirty water specimens were collected from drinking water sources that appear to be free from phytoplankton, 70 specimens were collected from drinking water sources that contain phytoplankton from Sana'a city and surrounding villages. 500 ml fresh drinking water or $500 \mathrm{ml}$ fresh drinking water contain phytoplankton specimens were passed through the membrane filter, soaked first on alkaline peptone water then 2 loop-full of the culture broth streaked to the TCBS media, and then bacterial growth colonies were identified with standard bacteriological methods. Also 75 specimens from different places of sewage system of Sana'a city were collected. An equal amount of swage's water and enrichment media (alkaline peptone water) were mixed then incubated for 24 hours then sub-cultured to TCBS media after that bacterial growth colonies were identified with standard bacteriological methods.

The rate of V. cholerae was zero from drinking water sources or from sewages. V. algenolyticus was isolated from only one fee phytoplankton drinking water sources (rate $=0.8 \%$ ), while in drinking water sources that contain phytoplankton $V$. algenolyticus and $V$. fluvialis were isolated with rate equal to $4.3 \%$ and $25.7 \%$ respectively. The crude prevalence rate of potential pathogenic Enterobacteria was $78.5 \%$ for drinking water sources. The rate of Salmonella typhi, and Shigella species, in swages system were $16.4 \%$ for both of them, while V. cholerae rate was zero.

We conclude from this study that, the prevalence of Vibrio cholerae in drinking water sources and sewages in Sana'a city was zero, while others Vibrioes as V. algenolyticus and V.fluvialis were isolated. The prevalence rate of other pathogenic bacteria species that transmitted through water ingestion in drinking water sources was high which indicate human fecal contamination of water sources. The rate of contamination with these bacteria is higher than that reported from other Arabic countries. Also non-V.cholerae species were low in free phytoplankton sources, while high level of non-V.cholerae was present in phytoplankton sources.
\end{abstract}

Keywords: Sana'a; Yemen; Sewages; Vibrio cholera; Vibrioes; Water sources

\section{Introduction}

Members of the genus Vibrio cause a number of important infectious syndromes. Classic among them is cholera, a devastating diarrheal disease caused by $V$. cholerae that has been responsible for seven global pandemics and much suffering over the past two centuries. Epidemic cholera remains a significant public health concern in the developing world today [1]. Other Vibrioes caused by other Vibrio species include syndromes of diarrhea, soft tissue infection, or primary sepsis. All Vibrio species are highly motile, facultative anaerobic, curved gram-negative rods with one or more flagella. In nature, Vibrioes most commonly reside in tidal rivers and bays under conditions of moderate salinity. They proliferate in the summer months when water temperatures exceed $20^{\circ} \mathrm{C}$. As might be expected, the illnesses they cause also increase in frequency during the warm months [2,3]. 
There are no records of any studies in which Vibrioes have been studied in aquatic environment in Yemen, so in the present study, we tried to isolate Vibrioes in TCBS selective media from different sources of drinking water in Sana'a. Vibrioes spp., such as Vibrio cholerae, Vibrio parahaemolyticus and Vibrio vulnificus, are commonly found in different aquatic environments, and can cause infections in humans. The most well-known serotypes are $V$. cholerae 01 and 0139, the causative agents of cholera, a gastrointestinal infection killing several hundred annually in Yemen. At present, cholera cases are very common in Yemen due to bad sanitation conditions and water contamination with human waste particularly in rural areas in the governorates of Hajjah, AlMahweet and Hodeadah [4]. However, cases of ear as well as wound infections caused by non-01 and non-0139 V. cholerae serotypes are not known or have not been reported from Yemen [4]. Thus far, there are no records of any studies in which Vibrioes contaminations have been studied in aquatic environment in Yemen, so in the present study, we tried to isolate vibrioes in Thiosulfate citrate bile salt media (TCBS) selective media from different sources of drinking water, in addition from swages system in Sana'a city.

\section{Material and Methods}

\section{Water specimen collection}

Specimens of water (fresh water $=500 \mathrm{ml}$, plankton sample water $=500 \mathrm{ml}$ ) were collected in sterile containers according to the standard method of "Bacteriological examination of water": A Medical microbiological techniques" [5]. All specimens were transported within two hours of collection to the Central Health Laboratory for processing, culture and identification.

\section{Laboratory investigations}

The volume of water specimen was passed through the membrane filter $(0.45 \mu \mathrm{m}$ polycarbonate membrane filters). After filtration, the membrane was transferred aseptically to $75 \mathrm{ml}$ alkaline peptone water media then incubated for 6 hours. Then 2 lupfuls of culture broth were streaked onto TCBS media. After 24 hours of incubation, colonies that have been developed on the surface of the media were identified.

\section{Sewage specimen collection}

Specimens of sewage $(250 \mathrm{ml})$ were collected in sterile containers according to the standard method of "Bacteriological examination of sewage water": A Medical microbiological techniques" [5]. Then equal amount of the specimen $(100 \mathrm{ml})$ and enrichment media $(100 \mathrm{ml})$ (Alkaline peptone broth) was mixed and transported to the Central Health Laboratory for processing, culture and identification.

\section{Laboratory investigations}

The sewage water specimen with alkaline peptone water then subculture to TCBS media. After 24 hours of incubation, colonies that have been developed on the surface of the media were identified.

\section{Microbiological examination}

Culture media: Thioglycolate, citrate bile sucrose agar (TCBS) was inoculated with collected specimens, and then incubated aerobically for culture the etiological agents. Vibrio species are sucrose or non-sucrose fermenting and therefore produces Yellow $2-3 \mathrm{~mm}$ in diameter colonies or green blue $2-3 \mathrm{~mm}$ in diameter colonies on the TCBS agar, also occasionally Aeromones species and Enterococci were produced small yellow colonies. Proteus strains were produce yellow colonies with black centers and some pseudomonas strains formed small green colonies.

\section{Isolation and identification of bacterial isolates}

Standard method of isolation and identifications were used to isolate bacteria in pure culture. Then they were identified by microscopy, gram reactions, and proper enzymes detections and biochemical reactions.

\section{Identification of a suspected vibrio isolates}

First oxidase test was performed by collecting colonies from TCBS then the test was performed as described by Cheessbrough [6]. Second step of identification is by examining a gram stained smear for gram negative vibrio. Lastly the suspected colonies subculture into sodium chloride free peptone water, peptone water containing $80 \mathrm{~g} / \mathrm{l}$ sodium chloride, then the inoculated media incubated at $37^{\circ} \mathrm{C}$ for 6 hours. An isolate can be identified presumptively as vibrio if it is sucrose or non-sucrose fermenting, oxidase positive, gram negative, does not grow in sodium chloride free peptone water but grow in $80 \mathrm{~g} / \mathrm{l}$ sodium chloride peptone water.

\section{Confirmatory identification by API-20 system}

The system consists of a plastic strip with 20 miniaturized cupules containing dehydrated substrates similar to the conventional tube biochemical tests and plastic incubation chamber with a loosely fitting lid. Each cupule has a small hole at the top. When freshly prepared bacterial suspension was inoculated into these wells and incubated in humidified chamber for $24 \mathrm{~h}$ at $37^{\circ} \mathrm{C}$, the resultant metabolism produces a color changes that are either spontaneous or revealed by addition of reagents. The reaction could be read according to the interpretation table and the identification was obtained by analytical profile index.

\section{Results}

Table 1: The bacterial growth percentage in different types of drinking water sources in Sana'a, Yemen 2009.

\begin{tabular}{|c|c|c|c|c|c|}
\hline Water sources & Number of samples tested & Positive bacterial growth & $\mathbf{\%}$ & Negative bacterial growth & \% \\
\hline Deep well & 35 & 31 & 88.6 & 4 & 11.4 \\
\hline Bottled water & 35 & 26 & 74.3 & 9 & 25.7 \\
\hline House ground reservoirs & 30 & 26 & 86.7 & 4 & 13.3 \\
\hline Tanks & 30 & 19 & 63.3 & 36.7 \\
\hline Total & 130 & 102 & 78.5 & 28 \\
\hline
\end{tabular}


During the six months period of the study, 130 fresh water samples were collected from different water sources in Sana'a city and surrounding villages. Table 1 shows the percentage of positive bacterial growth in different types of drinking water sources. The positive growth rates in deep well was $88.6 \%$, the growth rate of bottled water was $74.3 \%$, of house ground reservoirs was $86.7 \%$, and positive bacterial growth rate of tanks water was $63.3 \%$. The total growth rate for bacteria that grow in TCBS media from drinking water sources was $78.5 \%$.

Table 2: The types of isolated bacteria that grow on TCBS media from 130 samples which were collected from130 different drinking water sources in Sana'a, Yemen 2009

\begin{tabular}{|c|c|c|c|c|}
\hline Organisms & Number & $\%$ & T-test & PV \\
\hline Pseudomonas species & 36 & 27.7 & \multirow{11}{*}{15.4} & \multirow{11}{*}{$>0.01$} \\
\hline Klebsiella species & 18 & 13.8 & & \\
\hline Proteus species & 16 & 12.3 & & \\
\hline Citrobacter species & 11 & 8.5 & & \\
\hline Aeromonas species & 7 & 5.4 & & \\
\hline Alcaligenes species & 4 & 3.1 & & \\
\hline Staphylococcus aureus & 3 & 2.3 & & \\
\hline Shigella species & 3 & 2.3 & & \\
\hline E. coli & 2 & 1.5 & & \\
\hline V. algenolyticus & 1 & 0.8 & & \\
\hline Salmonella species & 1 & 0.8 & & \\
\hline
\end{tabular}

Positive percentage for each bacteria was calculated from the total 130 samples.

One or more bacteria can be isolated from the same sample.

Table 2 shows the types of isolated bacteria that grown on TCBS media from water samples which were collected from 130 different drinking water sources in Sana'a governorate. Pseudomonas species was the predominant organism, with 36 culture positive $(27.7 \%)$, followed by Klebsiella species with 18 isolates (13.8\%), then Proteus species 16 isolates(12.3\%), Citrobacter species with 11 isolates (8.5\%), Aeromonas species (isolates, 5.4\%), Alcaligenes species with 4 isolates ( $3.1 \%$ ), Shigella species with 3 isolates ( $2.3 \%$ ), E.coli with 2 isolates (1.5\%) and V. Algenolyticus and Salmonella species with 1 isolate $(0.8 \%)$.

Table 3: The types of isolated bacteria from 75 samples which were collected from sewage systems that grown on TCBS media, in Sana'a, Yemen.

\begin{tabular}{|c|c|c|c|c|}
\hline Organisms & Number & $\mathbf{\%}$ & T-test & PV \\
\hline Proteus species & 40 & 53 & & \\
\cline { 1 - 3 } Salmonella species & 19 & 25 & & \\
\cline { 1 - 3 } E. coli & 10 & 13.3 & \multirow{2}{*}{13.6} & \multirow{2}{*}{$>0.01$} \\
\cline { 1 - 3 } Pseudomonas species & 7 & 9 & & \\
\cline { 1 - 3 } Shigella species & 6 & 8 & & \\
\cline { 1 - 3 } V. algenolyticus & 2 & 2.6 & & \\
\hline Klebsiella species & 2 & 2.6 & & \\
\hline Citrobacter species & 2 & 2.6 & & \\
\hline
\end{tabular}

Positive percentage for each bacteria was calculated from the total 75 samples.

One or more bacteria can be isolated from the same sample.
Table 3 shows the types of isolated bacteria that grown on TCBS media from sewage samples. Proteus species was the predominant organism (53\%), followed by Salmonella species (25\%), Esherichia coli (13.3\%), then Pseudomonas species (9\%), Shigella species (8\%); and V. alginolytius, Citrobacter species and Klebsiella species with 2 isolates $(2.6 \%)$ for each one.

Table 4: The types of isolated bacteria that grown on TCBS media from samples which were collected from 70 different water with phytoplankton sources in Sana'a, Yemen 2009.

\begin{tabular}{|c|c|c|c|c|}
\hline Organisms & Number & $\%$ & T-test & PV \\
\hline Vibrio fluvialis & 18 & 25.7 & \multirow{10}{*}{7.5} & \multirow{10}{*}{0.01} \\
\hline Proteus species & 17 & 24.3 & & \\
\hline Salmonella species & 14 & 20 & & \\
\hline Aeromonas species & 13 & 18.6 & & \\
\hline Citrobacter species & 8 & 11.4 & & \\
\hline Shigella species & 6 & 8.6 & & \\
\hline Alcaligenes species & 4 & 5.7 & & \\
\hline Klebsiella species & 4 & 5.7 & & \\
\hline V. algenolyticus & 3 & 4.3 & & \\
\hline Pseudomonas species & 3 & 4.3 & & \\
\hline
\end{tabular}

Positive percentage for each bacteria was calculated from the total 70 samples.

One or more bacteria can be isolated from the same sample.

Table 4 shows the types of isolated bacteria that grown on TCBS media from water with phytoplankton samples. Vibrio fluvialis was the predominant organism (25.7\%), followed by Proteus species (24.3\%), Salmonella species (20\%), Aeromonas species, (18.6\%) and Shigella species (8.6\%). Also, positive rate were found with, Citrobacter species (11.4\%), Klebsiella species (5.7\%), Alcaligenes species (5.7\%) and Pseudomonas species (4.3\%) (Table 4).

\section{Discussion}

Water sources contamination is nearly always the result of human activities. Drinking water source is especially vulnerable in areas where population density is high and human use of the land is extensive. Virtually any activity whereby chemicals or wastes may be released to the environment, either intentionally or accidentally, has the potential to pollute water sources. All sources that studied by us are often used as sources of drinking water and it is known that if human consumption of water containing intestinal pathogens as $V$. cholerae may spread disease [7]. When water sources become contaminated, it is difficult and expensive to purify. Liquid waste discharged onto soil initiates solute and microbe movement is the main source that contaminates water sources $[7,8]$.

Only one sample of tested drinking water samples from sources free from phytoplankton was positive for $V$. algenolyticus (rate=0.08), and all types of water tested in our study was negative for $V$. cholerae and other Vibrioes species (Table 2). This low rate of Vibrioes in these sources in Yemen in spite of the effort that has been directed toward maximizing the detection of Vibrioes bacteria in the environment by using selective media as TCBS and by pass large amount of water through membrane filter as have been recommended [9]. Our result was different from that in Asia, Africa 
and Latin America where all species of Vibrioes including V. cholerae were isolated from aquatic environment [10-14]. The absent or low rate in the present study can be explained by that: first by the low level of plankton present in this aquatic environment in Sana'a city which works as nutritional factor for Vibrio's growth and multiplication, this fact confirmed by previous studies carried out in several countries which demonstrated adherence of Vibrioes to plankton that work as nutrient factor that help Vibrioes to survive and multiply in fresh water [15-18]; the second explanation is the possibility that erroneous conclusions about the low level of isolated Vibrioes may be related to size miniaturization of Vibrioes, resulting in non-detection of cells when standardporosity membrane filters are used for enumeration isolation. This suggestion can be confirmed by findings of Lappin-Scott and others [19] that state "The morphology of bacteria is related to their existence and persistence in the natural habitat and includes adaptations to low-nutrient environments", also large reductions in cell size have been reported as a specific physiological survival response by microorganisms in oligotrophic environments [20].

In vitro studies using long periods of starvation have suggested that one possible survival mechanism of bacteria in fresh water as drinking water is a decrease in cell size from large rods to small cocci. Pardio \& Violeta [9] reported that prolonged starvation of Pseudomonas aeruginosa in sterile, nutrient-free seawater resulted in the development of small cells capable of passing through a $0.45-\mu \mathrm{m}$-poresize membrane. These observations are reassuring, because evaluations of the bacteriological quality of drinking water from the sources that are free from Vibrioes are apparently not compromised because of a failure to detect miniaturized Vibrioes bacteria.

When water sources contains phytoplankton tested for the present of bacteria particularly Vibrioes; $V$. fluvialis was the predominant Vibrioes with positive rate equal to $25.7 \%$, followed by $V$. alginolytius with rate equal to $4.3 \%$. This result is lower than that reported from Latin America from water sources contain phytoplankton [21]. On other hand this result is higher than that occurred in deep well water samples or house-ground reservoirs where only $V$. algenolyticus isolated $2.9 \%$ were. This result confirmed the previous findings which plankton works as nutritional factor for Vibrio's growth and multiplication [16-18].

In addition, other potential pathogenic human sources bacteria were contaminated water sources that contain phytoplankton, and the level of contamination was higher than that of free drinking water sources (Table 2). These high rates of intestinal bacteria could be good indicator for human waste contamination in these open sources. This result is different from that reported elsewhere for open sources of fresh water as river [11].

Historically, the evaluation of the sanitary quality of drinking water has focused on enteric microorganisms associated with fecal pollution. More recently, efforts have been directed toward isolation and identification of non-enteric bacteria [7]. The possible public health significance of non-enteric bacteria in drinking water demands such attention. In particular, the presence of excessive background bacteria could potentially mask the presence of pathogenic as Vibrioes, thereby compromising the evaluation of the water's safety [22]. In addition to their importance as Vibrioes and Enterobacteria form antagonists, some opportunistic pathogens such as Aeromonas, Acinetobacter and Pseudomonas species [8]. For these reasons, in the present study we isolated and identified other opportunistic pathogens as Aeromonas species, Proteus species, and Pseudomonas species etc. to correctly evaluate the sanitary quality of drinking water. The positive bacterial growth rate for potential pathogenic bacteria from the different types of drinking water sources in the present study was very high' ranged from $63.3 \%$ to $88.6 \%$. This result is very high in contrast with that reported by Mahfouz et al. [23] in Sebha city for ground water sources where the rate of filterable bacteria was $42 \%$ cultivated in non-selective media. This high rate of bacteria growth in our study suggested high level of contamination of drinking water with human or animal intestinal bacteria even for bottled water which should be free from bacteria (Table 1). This result can be explained by that wastes are extensively released to the environment either intentionally or accidentally in Yemen more than elsewhere, which has the potential to pollute drinking water sources.

Table 2 shows that most even all isolated bacteria in our study were intestinal bacteria, some of them are very virulent human pathogens as Shigella species and Salmonella species, which confirmed the contamination of some drinking water tested with human wastes since human is the only reservoir for Shigella species [2].

Pseudomonas species was the predominant bacteria that isolated in our study, this result is similar to that reported elsewhere where Pseudomonas species was the predominant bacteria isolated from drinking water sources $[8,23]$. The presence of excessive nonenteric bacteria as Pseudomonas species could potentially indicate the presence of Coliforms of human sources; thereby indicate fecal contamination of water, thereby compromising the evaluation of the water's safety [24].

Aeromonas species was isolated in high rate in the present study from the sources of drinking water. Aeromonas species is known to be opportunistic pathogens responsible for diarrheal diseases [25], so possibility for large number of clinical cases of diarrheal diseases among infants, children, elderly and immunocompromised patients could be not missed in Sana'a city, due to consumption of the contaminated water.

The second aim of our study was to isolate V.cholerae and other virulent entero-pathogenic bacteria as Salmonella typhi and Shigella species from sewages as predicators for future epidemic of cholera, typhoid, or shigellosis due to the possibility of contamination drinking water with swages. The rate of V.cholerae was zero, but Salmonella typhi and Shigella species were isolated with high rate. Salmonella typhi and Shigella species were predominantly isolated from hospital swages, this result indicate the disposing of human execrations from hospitals without proper treatment to kill pathogens. The occurrence of Salmonella typhi and Shigella species in our study is different from that reported from Latin 
America [23], Since all hospital's wastes elsewhere is go-through disinfection treatment to kill pathogens before disposing to public swages [26,27].

\section{Conclusion}

We conclude from this study that, the prevalence of Vibrio cholerae in drinking water sources and sewages in Sana'a city was zero, while others Vibrioes as Valgenolyticus and V.fluvialis were isolated. The prevalence rate of other pathogenic bacteria species that transmitted through water ingestion in drinking water sources was high which indicate human fecal contamination of water sources. The rate of contamination with these bacteria is higher than that reported elsewhere. Also non-V.cholerae species were low in free phytoplankton sources, while high level of non-V.cholerae was present in phytoplankton sources. Also, serious pathogens as Salmonella typhi and Shigella species were predominantly isolated from hospital swages.

Based on the results of this study, Ministry of Agriculture and Ministry of Health and population: should establish centers with suitable equipments and materials to supervise and inspect the safety of drinking water sources, and to investigate the sources of contaminants of aquatic environments for prevention and controls diseases transmitted through ingestion contaminated drinking water. In addition, they should establish a policy for treatment and disinfection the disposing infectious material from hospitals and health centers for prevention and controls diseases transmitted.

\section{References}

1. WHO (2008) Cholera: prevention and control. Health topics. WHO.

2. Ryan KJ, Ray CG (2004) Sherris Medical Microbiology ( $4^{\text {th }}$ edn), McGraw Hill, pp. 376-377.

3. McLaughlin JB, DePaola A, Bopp CA, Martinek KA, Napolilli NP, et al. (2005) Outbreak of Vibrio parahaemolyticus gastroenteritis associated with Alaskan oysters. N Engl J Med 353(14): 1463-1470.

4. Ministry of Health and Population. NewsLetter 2010, no 12. Sana'a, Yemen.

5. Baker MB, Seiglie GA (2001) Water Microbiology. University of Peatras press. Medical school, Dept. of public health. pp: 260-320.

6. Chessssbrough M (2000) Manual of medical microbiology. ( $3^{\text {rd }}$ edn), Oxford press, pp. 231.

7. Entry JA, Farmer N (2001) Movement of coliform bacteria and nutrients in ground water flowing through basalt and sand aquifers. J Environ Quality 30(5): 1533-1539.

8. Lamka KG, LeChevallier MW, Seidler RJ (1980) Bacterial contamination of drinking water supplies in a modern rural neighborhood. Appl Environ Microbiol 39(4): 734-738.

9. Pardio S, Violeta T (2008) Impact of Climate and Environmental Factors on the Epidemiology of Vibrio cholerae in Aquatic Ecosystems. In: Hofer, Tobias N (Ed.), Marine Pollution. New Research, Nova Science Publishers, pp. 448, pp. 221-254,
10. Swerdlow DL, Mintz ED, Rodriguez M, Tejada E, Ocampo C. et al. (1992) Water-borne transmission of epidemic cholera in Trujillo, Perú: lessons for a continent at risk. Lancet 340(8810): 28-33.

11. Siddique AK, Zaman K, Baqui AH, Akram K, Mutsuddy P, et al. (1992) Cholera epidemics in Bangladesh:1985-1991. J Diarr Dis Res 10(2): 79-86.

12. Weil 0, Merche P(1992) The cholera epidemic in Ecuador: towards and endemic in Latin America. Rev Épidémiol Santé Publique 40(3): 144145 .

13. Sack RB, Siddique AK, Longini IM Jr, Nizam A, Yunus M, et al. (2003) A 4-year study of the epidemiology of Vibrio cholerae in four rural areas of Bangladesh. J Infect Dis 187(1): 96-101.

14. Lipp EK, Rivera IN, Gil AI, Espeland EM, Choopun N, et al. (2003) Direct detection of Vibrio cholerae and ctxA in Peruvian Coastal Water and Plankton by PCR. Appl Environ Microbiol 69(6): 3676-3680.

15. Reasoner DJ, Geldreich EE (1985) A new medium for the enumeration and subculture of bacteria from potable water. Appl Environ Microbiol 49(1): 1-7.

16. Borroto RJ (1997) Ecology of Vibrio cholerae sero group 01 in aquatic environments. Rev Panam Salud Pública 2: 328-333.

17. Gonçalves E, Da G Lopes M J et al. (2004) Associação de Vibrio cholerae com o zooplâcton de águas estuárias da Baía de São Marcos/São LuisMA, Brasil. Rev Soc Bras Med Trop 37(4): 318-323.

18. Pascual M, Rodó X, Ellner SP, Colwell R, Bouma MJ (2000) Cholera dynamics and El Nino-Southern Oscillation. Science 289(5485): 17661769.

19. Lappin-Scott HM, Cusack F, MacLeod A, Costerton JW (1988) Starvation and nutrient resuscitation of Klebsiella pneumoniae isolated from oil well waters. J Appl Bacteriol 64(6): 541-549.

20. Lillis TO, Bissonnette GK (2001) Detection and characterization of filterable heterotrophic bacteria from rural groundwater supplies. Lett Appl Microbiol 32(4): 268-272.

21. Claudia T Seeligmann, Virginia Mirande, Beatriz C. Tracanna, Clara Silva, Olga Aulet, et al. (2008) Phytoplankton-linked viable non-culturable Vibrio cholerae o1 from rivers in Tucuman, Argentina. J Plankton Research 30(4): 367-377.

22. Gotuzzo E, Cieza J, Estremadoyro L, Seas C (1994) Cholera, lessons from the epidemic in Peru. Infect Dis Clin N Am 8(1): 183-205.

23. Mahfouz SA, Shaieb FM, Elzen AEK (2008). Detection and identification of ground water bacteria in Sebha City, Libya. African Journal of Microbiology Research 2: 224-228.

24. Marquis GS, Ventura G, Gilman RH, Porras E, Miranda E, et al. (1990) Fecal contamination of Shanty town toddlers in households with noncorralled poultry, Lima, Peru. Am J Public Health 80(2): 146-149.

25. Drasar BS, Forrest Bruce D (2008) Cholera and the ecology of Vibrio cholerae. Springer. pp. 355.

26. Glass RI, Claeson M, Blake PA, Waldman RJ, Pierce NF (1991) Cholera in Africa: Lessons on transmission and control for Latin America. Lancet 338(8770): 791-795.

27. Madico G, Checkley W, Robert H (1996) Active surveillance for vibrio cholerae 01 and vibrio phages in sewage. Water as a Potential tool to predict cholera outbreaks. J Clinical Microbiol 34(12): 2968-2972. 